\title{
Clarifying "Fuzzy"
}

\section{Hospitality-management Problems with}

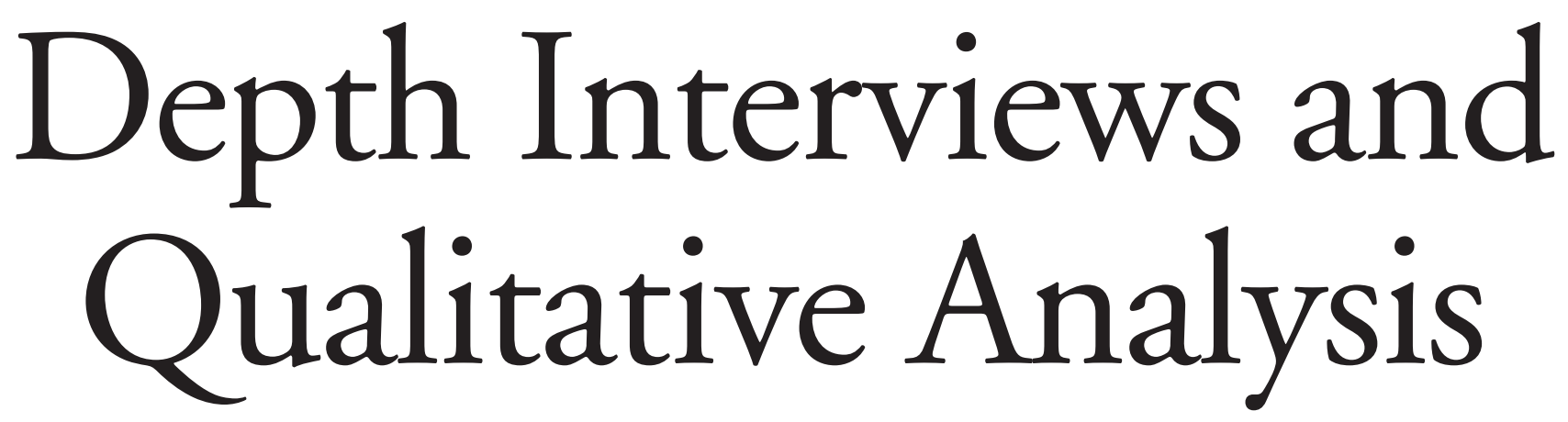

\section{Properly conducted depth interviews can dig to the sometimes-confusing heart of consumers' motivation for hospitality purchases.}

BY ROBERT J. KWORTNIK, JR.

$\mathrm{M}$ any successful hospitality-management programs are predicated on the manager's ability to get to know the customer, a task that is almost always easier said than done. The depth of understanding required to answer certain customer-related questions is often difficult to reach with traditional research tools such as surveys. Consider, for example, questions related to consumer decision making. Conventional wisdom suggests that a consumer's choice of hospitality products is based on both rational and emotional considerations. That is, there is a logical component to the decision, in which the buyer considers such attributes as price, location, and ratings of service quality. There is also an emotional component, such as feelings of happiness and excitement, which are elicited by the decision itself and by emotionally evocative aspects of the choice options. The emotional aspects are likely to be strongest when a choice is made more for hedonic rea- sons (e.g., pleasure travel) than for utilitarian reasons (e.g., business travel).

The above discussion raises the question of what we know about how, when, and why positive emotions come into play in such a choice process. The answer is, surprisingly little, even though all manner of strategic decisions associated with the marketing of hospitality products, from product and service design to marketing promotion, involve some emotion quotient. Such limited knowledge about a topic of importance to managers and customers alike has a number of causes. Perhaps the chief cause is simply that positive emotion is an ambiguous construct that is hard to define and even harder to study. Indeed, despite centuries of theorizing about and studying emotion, there remains little consensus as to what emotion really is and how best to measure it.

() 2003, CORNELL UNIVERSITY 
Research on emotion and consumer decision making represents what one might call a "fuzzy" problem. Similar problems involve other aspects of consumer psychology, such as the roles of status, self-identity, or culture in hospitality consumers' behavior. Interest in these problems is more than just academic, especially as we strive to make sense of rapid changes in consumer preferences. For example, if one wants to understand the recent success of boutique hotels or the boom in adventure travel, it is not enough merely to identify which consumers are driving those trends. One also needs to understand what is driving these consumers, or the "why" behind their behavior.

Fuzzy research problems are marked by a limited or evolving understanding of the phenomenon of interest (e.g., how is emotion experienced during decision making?), questions about construct validity (e.g., what exactly is emotion in this context?), and a host of measurement challenges (e.g., can consumers express how they really feel during a decision, and if they can, will they?). Because of such issues, fuzzy problems can be a challenge to study using survey or experimental research methods, where reliable measures are needed to use the statistical-analysis tools that lend such methods inferential power. Research methods of that kind also depend on a sound theoretical framework that anchors the research design. Absent a guiding theory and conceptual clarity, it becomes difficult, if not impossible, to know what research questions to ask or how to ask them.

Fortunately, qualitative-research methods are available for examining fuzzy problems. Qualitative approaches are intended to generate a deeper understanding of complicated behavior, rather than to quantify, generalize, or predict it. ${ }^{1}$ In other words, qualitative research can help managers learn how consumers think and feel, including plumbing the reasons for those thoughts and feelings that may be difficult for consumers to express or are even beyond their

\footnotetext{
${ }^{1}$ L.A. Hudson and J.L. Ozanne, "Alternative Ways of Seeking Knowledge in Consumer Research," Journal of Consumer Research, Vol. 14 (March 1988), pp. 508-521. See also: K. Walsh, "Qualitative Research: Advancing the Science and Practice of Hospitality," in this issue of Cornell Hotel and Restaurant Administration Quarterly.
}

awareness. ${ }^{2}$ In this way, qualitative research can help managers develop theories to explain consumer behavior and, consequently, identify possible strategies for influencing that behavior. However, these research methods are not designed to tell managers how many or what proportion of a population thinks or feels a certain way, or whether use of a particular strategy will cause some desired result. Such questions are better answered by quantitative-research methodologies.

This article describes qualitative-research methodologies, depth interviewing and interpretive analysis, that are especially appropriate for hospitality research and exploring the "why" questions associated with consumer behavior and motivation. In the following section I give a brief description of depth interviewing, along with examples of appropriate research contexts for using depth interviews. This is followed by an outline of an approach for conducting, analyzing, and interpreting depth interviews. Finally, I offer recommendations and caveats for hospitality managers who might consider using depth interviews as a means for better focusing fuzzy problems and for developing theories to guide strategic action.

\section{The Depth Interview}

Interview procedures come in a number of forms, but can most easily be distinguished by the degree of structure used by the researcher in the interview process. ${ }^{3}$ At one end of the spectrum are highly structured, survey-driven interviews, where respondents answer predetermined questions, sometimes using only a set of closed-end responses (e.g., yes-no or multiple choice) or a combination of these and open-end questions. At the other extreme are unstructured interviews that are less like a question-and-answer session and more like an informal conversation between the researcher and the participant. A depth interview takes the general form of an informal conversation, but it constitutes a purposeful dialogue be-

\footnotetext{
${ }^{2}$ See: Walsh, loc. cit.

${ }^{3}$ E.J. Arnould and M. Wallendorf, "Market-oriented Ethnography: Interpretation Building and Marketing Strategy Formulation," Journal of Marketing Research, Vol. 31 (November 1994), pp. 484-504.
} 
tween a person, called an "informant," and a skilled researcher. ${ }^{4}$ Such interviews vary in length, but a one-hour discussion is common. The objective of the depth interview is to obtain rich, detailed data that reflect the informant's language, experience, and perspective "in depth." The most common type of depth interviews are semi-structured and feature some prearranged questions to guide the dialogue toward specific topics.

Depth interviews are purposeful in the sense that they are framed by some overarching research question or concern, even if the interview itself is unstructured and appears at least to the informant to lack direction. The interview is characterized by the use of general, descriptive questions that facilitate the dialogue, but which let the informant direct and provide the content of the interview. ${ }^{6}$ For example, a researcher might be interested in finding out what elements of a luxury-hotel stay are most important to status-conscious guests. Rather than ask this question directly, the interviewer could pose the broader question, "Tell me about a recent hotel experience that you enjoyed." Depending on how the informant responds, the interviewer might use additional probes to encourage the informant to express greater detail. For instance, if the informant answered, "We stayed in a luxurious suite with all the amenities," the interviewer might say, "You said your suite was luxurious. Tell me more about that." The product of this line of inquiry is a descriptive text that represents the informant's perspective. This text constitutes the data record for interpretive analysis.

\footnotetext{
${ }^{4}$ See: D.A. Erlandson, E.L. Harris, B.L. Skipper, and S.D. Allen, Doing Naturalistic Inquiry (Newbury Park, CA: Sage Publications, 1993), and L.A. Hudson and J.L. Ozanne, op. cit.

${ }^{5}$ See: Hudson and Ozanne, op. cit.; and S. Spiggle, "Analysis and Interpretation of Qualitative Data in Consumer Research," Journal of Consumer Research, Vol. 21 (1994), pp. 491-503.

${ }^{6}$ See: Arnould and Wallendorf, op. cit.; G. McCracken, The Long Interview (Newbury Park, CA: Sage Publications, 1988); and C.J. Thompson, W.B. Locander, and H.R. Pollio, "Putting Consumer Experience Back into Consumer Research: The Philosophy and Method of Existential Phenomenology," Journal of Consumer Research, Vol. 16 (September 1989), pp. 133-146.
}

\section{Fuzzy Research Problems and the Interview Structure}

The decision about how much to structure an interview depends in part on the clarity of the research problem —or lack thereof. This is by no means a trivial issue. As a general rule, the fuzzier the research question is, the less structured the interview should be. In other words, until the researcher is relatively clear on what is to be studied and how, the objective of the interview should

\section{Depth interviews are purposeful in the sense that they are framed by some overarching research question or concern.}

be discovery and enhanced understanding of the phenomenon. Such an understanding is derived from data grounded in the informants' experience-what they say about what they did, how they felt, or what they thought. Such a theorydevelopment objective usually demands an emergent design for the research process - one that is fluid and adaptable as concepts and relationships are revealed in the course of data collection, analysis, and interpretation. Unlike survey or experimental research that demands the investigator's intervention prior to data collection through the precise creation of a questionnaire or experimental design, qualitative methods such as depth interviews involve the researcher as an interpreter mostly during and after data collection.

Consider the research problem introduced in the opening of this article, which broadly addressed the way in which positive emotions come into play in the choice process for hospitality products. A similar question was the focus of a study I performed as part of a multimethod investigation of consumer decision making. ${ }^{7}$ One objective of this study was to develop a model of

\footnotetext{
${ }^{7}$ R.J. Kwortnik, "The Role of Positive Emotions in Consumer Choice for Experiential Products," Philadelphia: Temple University (doctoral dissertation), 2002.
} 
To uncover the relationships among a subject's answers demands an unobtrusive data-collection procedure and an incisive analytic approach. positive emotion and consumer choice and to test relationships in that model. However, the challenge of modeling positive emotion experienced during the decision process precluded a workable experimental design until it was clear how to manipulate and measure positive decision emotion. Because emotion is a vague construct, semi-structured depth interviews and interpretive analysis were used to gain insight into how consumers experienced positive emotion during choice. Although positive emotion was the main phenomenon of interest, my interview questions avoided the mention of the word "emotion." Instead, informants were asked to describe a recent vacation experience and the decision process that led up to that trip. This way, any a priori theory about the emotional nature of decision making was "bracketed," ${ }^{8}$ and the model of consumer choice that emerged was derived from the informant's voice and perception of reality.

\section{Sensitive Questions and the Interview Instrument}

It is important to keep in mind that the questions a researcher asks often shape and may bias the responses. For example, a question as seemingly straightforward as, "To what extent did price influence your purchase decision?" can encourage socially desirable responses. That is, informants who wish to present themselves as smart shoppers might say that price was duly considered, even though it was not. On the other hand, informants who wish to be perceived as lacking financial worries might say that price was not a factor when in fact it was. Either way, the validity of the response is undermined by the question. Another way to phrase this question might be, "What influenced your purchase decision," or more simply, "Tell me about the purchase process for this product."

If such response bias is a concern, depth interviews are a solution. This is because the informant is in charge of the discourse and is less apt to discern the researcher's underlying interest. Moreover, the informant is responding to general questions, not probes that he or she perceives

${ }^{8}$ See: Thompson et al., op. cit. to warrant some type of self-protective answer. For instance, in the study of positive emotion and consumer choice, ${ }^{9}$ informants were asked near the end of the interview whether emotion influenced their decision making. Some informants quickly responded that their decision was bereft of emotion-even if they had previously mentioned having fun planning, anticipating, and imagining the experience. This contradiction suggested a rationality bias. Indeed, in North American culture, emotional behavior is still considered irrational, despite recent research on the adaptive benefits of emotional intelligence. ${ }^{10} \mathrm{Had}$ I asked a direct question regarding the role of positive emotion in choosing a vacation earlier in the interview, the informants' self-protective behavior may have colored subsequent discussion.

Another example of a research question that is conceptually ambiguous and likely to elicit socially desirable responses was suggested earlier-namely, the roles of self-identity and status in the consumption of luxury brands. As a psychological construct, self-identity is another vague concept that is difficult for both researcher and informant to capture with precision. Moreover, as Catrett and Lynn noted in a Cornell Quarterly article on hotel-industry status brands, "Status seekers are loath to own up to trying to impress others, making empirical quantitative research difficult." ${ }^{11}$ No doubt, few luxury hotel patrons would point to status needs and self-identity issues as motivating their consumer behavior, even if it were true, and especially if they were asked directly about it. To uncover such a relationship demands an unobtrusive data-collection procedure and an incisive analytic approach. A means for accomplishing this is described next.

\section{Using Semi-structured Depth Interviews for Hospitality Research}

Depth interviews may seem easy enough to someone who has not tried doing one. After all, the

\footnotetext{
${ }^{9}$ See: Kwortnik, loc. cit.

${ }^{10}$ J. Ciarrochi, J.P. Forgas, and J.D. Mayer, Emotional Intelligence in Everyday Life: A Scientific Inquiry (Philadelphia: Psychology Press, 2001).

${ }^{11}$ J. Catrett and M. Lynn, "Managing Status in the Hotel Industry," Cornell Hotel and Restaurant Administration Quarterly, Vol. 40, No. 1 (February 1999), p. 27.
} 
task is merely to get an informant to open up, and who would not like to talk about experiences related to hospitality encounters? However, performing an interview that yields rich, detailed, and useful data involves skill and practice. Because depth interviews are largely directed and paced by the informants, they can drift away from the main topic of interest to the researcher. Even worse, some interviews with cautious or otherwise reticent individuals may never get going, despite the interviewer's best efforts to draw the informant out. People also can become guarded in their responses or just clam up if they feel threatened or if they determine that they are being analyzed. Just seeing a recording device, be it a video camera or a pencil, can make an informant uneasy. Then again, other informants may become loquacious when they see a researcher take notes because they perceive this action as an indication that what they are saying is important. The point is that no two interviews are alike, so there is no one right way to conduct an interview.

There are, however, many wrong ways to conduct an interview. Mistakes such as asking leading and loaded questions or the use of active listening and probing (described below) can produce data that are of little value or, worse, that generate illusory conclusions and consequent bad management decisions. This research method also requires substantial time, especially for transcribing, coding, analyzing, and interpreting interview data. Thus, it is not advisable to undertake a study using this methodology without the assistance of a trained interviewer and analyst, or, at least, without giving due diligence to literature that details the procedure. ${ }^{12}$ The outline of the methodology that follows is not intended to be a substitute for those sources, but instead to provide an introduction to the essentials of depth interviewing and analysis.

\section{The Research Plan}

The most important and challenging part of the research process is planning the task. It is here

\footnotetext{
${ }^{12}$ Two tractable and enjoyable books on the subject are: McCracken, op. cit.; and Anselm Strauss and Juliet Corbin, Basics of Qualitative Research, second edition (Thousand Oaks, CA: Sage Publications, 1998).
}

that you have to determine your research question and how best to answer it. Now is when one considers the "fuzziness" of the problem and makes decisions about the appropriate degree of structure for the interviews. The good news, though, is that, unlike many other data-collection tools, depth interviews are adaptable. In all likelihood, the questions used to propel the interviews for the first few informants will differ from questions used later in the sampling frame. This is consistent with the spirit of an emergent

\section{Performing an interview that yields rich, detailed, and useful data involves skill and practice.}

design for qualitative inquiry. ${ }^{13}$ As the researcher's understanding of the issues evolves, so does the research process.

How to sample. How many informants are appropriate for a qualitative study? Who should be selected? In contrast to quantitative research methods where large, random samples of subjects are typically needed to enable statistical analysis and support the generalizability of results,${ }^{14}$ informant samples for interpretive research tend to be relatively smaller and nonrandom. A sample as small as a dozen people might be appropriate for qualitative-research projects where the main objective is deeper understanding of some complex behavior or meaning. ${ }^{15}$ Even a sample of this size can produce considerable data, though. For example, I conducted a dozen depth interviews for the study of positive emotion and consumer choice noted earlier. These interviews produced more than 200 pages - nearly 4,500 double-spaced lines_of textual data. ${ }^{16}$

\footnotetext{
${ }^{13}$ See also: Walsh, loc. cit.

${ }^{14}$ See: M. Lynn, "Experiments and Quasi-experiments: Tools for Evaluating Marketing Options," in this issue of Cornell Hotel and Restaurant Administration Quarterly.

${ }^{15} \mathrm{McC}$ racken, op. cit.

${ }^{16}$ Kwortnik, loc. cit.
} 
The decision about how many informants are needed for depth interviews is not predetermined, but instead flows from the research process. Analysis of interview data usually occurs early in the data-collection stage-sometimes after the first interview. Findings from initial interviews are provisional and help to shape subsequent interviews. These new interviews are conducted up to the point when the researcher feels that redundancy or theoretical saturation has been achieved, where no new insights emerge from the

\section{The success of a depth interview depends on the interviewer's ability to get the respondent to speak freely about personal topics.}

analysis of an additional case. ${ }^{17}$ This might occur after interview number 10, 20, or 50 .

Selection of interview informants is also driven by objectives other than generalizability. Thus, it is not necessary that the sample be representative of the total customer population. A researcher might choose to interview loyal customers, prospective customers, noncustomers, or any combination of these categories - whatever individuals are most likely to provide the data needed to shed light on the research question. For instance, if a researcher is studying the influence of need for status on hotel choice, informants might be recruited from the guest list at just one luxury hotel. If generalizability of the findings to a larger population is desired, a random sample of informants drawn from the population of interest or another research approach (e.g., experimentation $)^{18}$ or research tool (e.g., a survey) ${ }^{19}$ might be used based on the findings from the qualitative study.

Preparing for depth interviewing. The success of a depth interview depends on the

\footnotetext{
${ }^{17}$ Strauss and Corbin, op. cit.

${ }^{18}$ Lynn, loc.cit.

${ }^{19}$ See: M. Schall, "Best Practices in the Assessment of Hotel-guest Attitudes," in this issue of Cornell Hotel and Restaurant Administration Quarterly.
}

interviewer's ability to get the respondent to speak freely about personal topics. Interview participants face perceived risks, including wasting their time and emotional stress. Thus, it is vital that the researcher establish trust and rapport with participants. In some qualitative studies, trust is achieved through participant observation, where the researcher joins in the activities and engages in the behaviors of a culture. For example, in a remarkable study that sought to clarify the fuzzy question of what motivates people to engage in high-risk leisure activities, a researcher became a member of a skydiving club and made some 650 jumps (as well as conducting 35 depth interviews) as part of the study. ${ }^{20}$

Needless to say, less-involved methods of developing rapport with informants are available. For instance, at the onset of an interview, the researcher or interviewer should introduce herself and give at least a general explanation of the study's purpose. Assurances of data confidentiality and the informant's anonymity can also enhance trust and reduce the chance that participants will try to play the role of "good subjects" by telling the interviewer what they think he or she wants to hear. ${ }^{21}$ It is also important to obtain written informed consent and additional permission if audio or video taping will be used. Audio or video taping can be obtrusive, although informants often forget they are being recorded. More important, audio or video tapes provide a data record for later transcription and also free the interviewer from constant note taking, thereby allowing for enhanced focus on the discourse.

The interviewer's ability to put the informant at ease is also a function of the relationship that the interviewer establishes. Thompson et al. suggest that the interviewer and informant are equals and that the interviewer should avoid being perceived as more powerful or as an expert. ${ }^{22}$ McCracken, on the other hand, argues for a balance between formality and informality, with the

\footnotetext{
${ }^{20}$ R.L. Celsi, R.L. Rose, and T.W. Leigh, "An Exploration of High-risk Leisure Consumption through Skydiving," Journal of Consumer Research, June 1993, pp. 1-23.

${ }^{21}$ R.L. Rosnow and R. Rosenthal, People Studying People: Artifacts and Ethics in Behavioral Research (New York: W. H. Freeman and Company, 1997).

${ }^{22}$ Thompson et al., op. cit.
} 
interviewer cast as a scientist, "...someone who asks personal questions out of not personal but professional curiosity." ${ }^{23}$ In this role the interviewer uses cues such as dress, behavior, and language to establish the formality of the relationship and to reassure the participant that the researcher can be trusted. In yet other instances, for example where emotional openness and some understanding of the informant's personal history is desired, it may even be appropriate for the interviewer and informant to be acquainted and for the interview to occur informally. ${ }^{24}$

Getting started. Regardless of the degree of formality in the interviewer-informant relationship, depth interviews are most effective when the informant feels relaxed and safe and the interaction is conversational. This tone is set early on by, for example, beginning with idle chatter. ${ }^{25}$ This is also when the interviewer should start any recording device and begin to take notes. This not only will cue the informant as to what behavior to expect of the researcher, but if there is any initial discomfort with data recording, it is more likely to be experienced then and not later when the key interview questions are being asked.

Some interviewers also commence depth interviews with biographical questions. However, even asking about age, marital status, or employment early in an interview can be perceived as intrusive and may make an informant defensive. For this reason, other researchers hold such questions until the end of an interview, when informants have a vested interest in completing the encounter. An alternative to small-talk interview openers are novel, ice-breaker activities. For example, in the study of positive emotions and consumer choice, I used a projective exercise to elicit informants' perceptions of themselves and of selfrelated concepts. ${ }^{26}$ The exercise involved word-

\footnotetext{
${ }^{23}$ McCracken, p. 26.

${ }^{24}$ L.L. Price, E.J. Arnould, and C.F. Curasi, "Older Consumers' Disposition of Special Possessions," Journal of Consumer Research, Vol. 27 (September 2000), pp. 179201. See also: Kwortnik, loc. cit.

${ }^{25}$ McCracken, op. cit.

${ }^{26}$ Kwortnik, loc.cit. This exercise was adapted from one used by: H.J. Schau, "Consumer Imagination: Identity and Self-expression in Consumer Mediated Environments," Irvine, CA: Graduate School of Management, University of California-Irvine (doctoral dissertation), 2000.
}

association and sentence-completion tasks. For each task, the researcher read a word (e.g., me, play, home, success) or sentence (e.g., "People tell me that I am...," "I vacation in order to...") and asked the informants to say the first word or phrase that came to mind or that would best complete the sentence. Participants were assured in a light-hearted manner that their answers were not going to be analyzed for a hidden psychosis. This exercise offered the dual benefit of opening the actual interview with a fun task, and also of providing the researcher with additional information used to form a more complete picture of the informant. Interestingly, some informants exposed to this exercise offered their own unprompted analyses of their answers, pointing out patterns in their responses that they found enlightening.

Guiding the interview dialogue. From this introductory stage, the depth interview progresses toward the main line of inquiry. This usually begins with a broad, nondirective "grand-tour question," ${ }^{27}$ such as the one mentioned earlier: "Tell me about a recent hotel experience that you enjoyed." The importance of skill in depth interviewing is most evident from this point forward. In highly unstructured interviews, the researcher links informant responses (e.g., "We stayed in a luxurious suite with all the amenities") with prompts or probes. Prompts might be nonverbal, such as facial expressions, a raised eyebrow, wrinkled forehead, or gaze of concentration that encourage informants to clarify or expand on their description. Similar verbal prompts include repeating specific informant words or phrases (e.g., "luxurious") or probes that directly ask for a more detailed explanation of a comment (e.g., "describe 'all the amenities").

The objective of prompts and probes is to reveal the often-hidden meanings in a person's experience, but from the informant's perspective. The key is to look for language that suggests a cultural or personal meaning that may be cloaked by the obvious. For example, although the term "luxurious" has a generally accepted definition, it likely means different things to different people. Uncovering these relative meanings can offer extraordinary insight as to what lodging consumers think of and seek in terms of luxury.

\footnotetext{
${ }^{27}$ McCracken, p. 35.
}

Depth

interviews are most effective when the informant feels relaxed and safe and the interaction is conversational. 
The challenge in probing for hidden meanings during the interview is to avoid injecting the dialogue with the researcher's own hypotheses or on-the-spot analysis. Here is where active listening can be a significant problem if it violates the "law of nondirection." 28 Active listening occurs when the interviewer inadvertently completes informants' thoughts or interprets the meaning of their statements for them. For instance, if the interviewer responded to the informant's comment about staying in a luxurious suite by saying something like, "Luxuriousno doubt expensive," this may not be the meaning the informant attached to the "luxurious" dimension of her hotel experience. It is easy for novice interviewers to fall victim to active listening, which is considered to be a useful skill in other contexts. But in depth interviews, this type of questioning can render useless otherwise valuable data.

A variety of other prompting techniques are available to the depth interviewer, but using them depends in part on one's research philosophy and in part on necessity. The techniques include the use of metaphor elicitation (e.g., "Staying in a hotel of this type is like..."), contrast prompts (e.g., "Describe the difference between luxurious accommodations and those which are not luxurious"), and exemplar prompts (e.g., "Describe something about your hotel stay that really stands out as luxurious"). There are also relatively invasive probes, such as the laddering interview technique, which involves asking participants about their responses to encourage their own interpretations of the underlying causes of and motivations for their behavior. ${ }^{29}$ This is done by asking a series of why questions, such as, "Why is it important to you that a hotel has 'all the amenities?" A response to this question (e.g., "Because I like to be pampered when I'm away from home") might elicit another "why" followup: "Why is it important to you to be pampered

\footnotetext{
${ }^{28}$ Ibid., p. 21.

${ }^{29}$ See: T.J. Reynolds and J. Gutman, "Laddering Theory, Method, Analysis, and Interpretation," Journal of Advertising Research, February-March 1988, pp. 11-31; and L. Dubé, M.D. Johnson, and L. M. Renaghan, "Adapting the QFD Approach to Extended-service Transactions," Production and Operations Management, Vol. 8, Fall 1999, pp. 116.
}

away from home?" This type of probing continues until a higher-order need or value is revealed (e.g., "Because I've worked hard to get where I am; I deserve the pampering").

The decision to use assertive probes should be carefully considered, for there are trade-offs in data integrity. Some qualitative researchers caution against asking informants "why" questions, because such inquiries require informants to step away from their actual experience and instead to speculate about and rationalize their own motives; that is, to perform a causal analysis as "naïve scientists." ${ }^{30}$ Rather, by seeking instead descriptions of experience, the researcher retains the interpretation task. However, as discussed in the following section, this analytic task is challenging, especially for the novice. Moreover, there may be research contexts for which it is appropriate to use otherwise intrusive interview probes to co-opt the informant as analyst, such as when the research objective is to understand what consumers think about what they do and why they do it.

\section{Depth Interview Data Analysis and Interpretation}

With descriptions of human experience as the data for analysis, what exactly is it that qualitative researchers seek? Unlike quantitative research, which seeks explanation and prediction through theory testing, qualitative research seeks understanding and discovery through theory building. ${ }^{31}$ Specifically, qualitative researchers look for categories, patterns, themes, and meanings both within and across the text of research participants. For example, in a fascinating study of multi-day river-rafting trips, researchers tackled the fuzzy problem of consumers' expectations for an experience that is labeled extraordinary. ${ }^{32}$ Using a multimethod research approach that included depth interviews, the researchers found that prepurchase expectations were often vague, such as "to have fun" or to "not get killed." As such, satisfaction with the experience was based not so

\footnotetext{
${ }^{30}$ Thompson et al., op. cit.

${ }^{31}$ Walsh, loc. cit.

32 E.J. Arnould and L.L. Price, "River Magic: Extraordinary Experience and the Extended Service Encounter," Journal of Consumer Research, June 1993, p. 24.
} 
much on a comparison with expectations (in contrast with the dominant theory of customer satisfaction) as it was on satisfaction with the narrative of the journey and experiential themes such as personal growth and harmony with nature. This theory of extraordinary experience also meant that strategies aimed at managing satisfaction according to guests' stated intentions were unlikely to be effective. Instead, managers should focus their attention on the structure of the narrative and the employees' ability to direct the story in a way that maximizes hedonic and emotional outcomes.

The method described here for analyzing depth-interview data is based on the groundedtheory approach to qualitative-data analysis described by Strauss and Corbin..$^{33}$ The process is systematic in that it involves a plan for developing a sensitivity to the meanings in interview data. The structure of the plan is an alternating sequence of data coding (what does this interview word or statement mean?), analytic abstraction and comparison (how do these meanings relate to form categories and themes?), and theoretical sampling of new data based on emergent concepts (how does a new piece of data fit into or alter the thematic scheme?). The mechanics of this systematic interpretive process are illustrated in the following section.

\section{The Analysis Process}

Analysis of depth-interview data takes place soon after the first interview or first few interviews are conducted. The raw product of an interview is usually an audio or video tape and the interviewer's written notes about the encounter. These items become the data source for analysis. The recorded dialogue is transcribed into a document with wide margins for notes and numbered lines for cataloguing units of data.

Coding data. Actual analysis begins with the researcher rereading the transcribed interview several times to become as familiar as possible with the informant's perspective of the discussion. Analysis then proceeds by deconstructing the text line by line, and in some instances, word by word, to "mine the data" for concepts that will form theoretical categories and relationships.

\footnotetext{
${ }^{33}$ Strauss and Corbin, op. cit.
}

This interpretive process essentially involves the naming or "open coding" of data using labels that reflect the meaning of the text. Sometimes such concept labels are provided by the informant or borrowed from the existing literature, but most often the labels are created by the analyst. Once identified, the labels are usually written or typed on the interview transcript near the elements of text the label was chosen to represent.

The major challenge when performing data coding involves thinking about the data in a way that not only takes into account the informant's perspective, but that also reveals meanings hidden beneath the surface of the informant's text. One straightforward way for doing this is analytic questioning. This simply involves asking, "What does this word or phrase really mean?" For example, if a hotel guest says, "I always like fresh flowers in the room," what does this really mean? Does this mean nothing more than what the guest said (label: fresh flowers)? Or, in the context of the dialogue and of the consumer's life, does this mean the guest likes what the flowers represent, from the more concrete (labels: freshness or cleanliness) to the more abstract (labels: renewal and youth or pampering and status)? Examining the data in this manner forces the analyst to do more than just read the text, but also to hear the informant's voice and to listen on a deeper level.

Another strategy for identifying key interview data points involves scanning for textual "red flags" that signal cloaked meanings, beliefs, and self-related perceptions. ${ }^{34}$ Researchers Arnould and Wallendorf have identified three such clues often found in verbal-report data: glosses, overgeneralizations, and claims to idiosyncrasy. ${ }^{35}$ Each of these can represent a jumping-off point for additional in-depth analysis of informants' text.

Glosses come in a variety of forms, from metaphorical statements that encode-or gloss overthe taken-for-granted meanings that informants ascribe to their behavior, to comparative state-

\footnotetext{
${ }^{34}$ Ibid.

${ }^{35}$ E.J. Arnould and M. Wallendorf, "Market-oriented Ethnography: Interpretation Building and Marketing Strategy Formulation," Journal of Marketing Research, Vol. 31, November 1994, pp. 484-504.
} 
The most important safeguard against the infusion of bias in qualitative research is the application by someone trained in interpretive science of a rigorous, tested method of analysis. ments about their behavior relative to what they perceive as being typical of others. For instance, in the following interview excerpt taken from the study of positive emotions and consumer choice, ${ }^{36}$ Ron, a male in his late 30 s, uses a number of glosses (in italics) to explain why he and his wife seek something "different" in their vacation experiences: ${ }^{37}$

R: Yeah, I think that's in our nature. We always look for things that are a little different. We taste a lot of things that tend to be different ... not between us, but what we like as opposed to most people. We kind of look for that unique thing.

Ron's "in our nature" and "taste a lot of things" metaphorical statements, in combination with his belief that he and his wife look for "that unique thing," gloss a set of personal and cultural meanings related to the perceived uniqueness (label) of vacation choices, and the belief that this search for the unusual is motivated by an innate drive, and not necessarily by a cultural norm - a theme common to several of the interviews done for this study. Interestingly, however, the vacations that Ron and his wife talked about most were a recent trip to Walt Disney World and a driving trip through Germany-neither one particularly off the grid. In Ron's case, his actual behavior suggests choices that are not necessarily unusualdespite his personal interpretation of those choices.

Ron's statement also contains two other clues to self-relevant meanings. The first is his overgeneralization, "We always look for things that are a little different," which is signaled by use of the absolute term, "always" (the term, "never," can also signal an overgeneralization). The second clue is Ron's claim to idiosyncrasy, "...what we like as opposed to most people." Similar to glosses, such statements reflect the informants' interpretation of behavior, regardless of what the actual behavior suggests. ${ }^{38}$ Such clues are also found in this excerpt from the text of another informant, Lisa, a 40-year-old mother of three, as she describes the role of cost in her family's vacation choices:

\footnotetext{
${ }^{36}$ See: Kwortnik, loc. cit.

${ }^{37}$ As is usually done in the reporting of qualitative research, informant identities are masked to protect their anonymity.

${ }^{38}$ Arnould and Wallendorf, op. cit.
}

L: I know a lot of people probably say, OK, I have "X dollars" and this is what I can spend on a trip. We've never ever looked at any of our vacations in terms of financial; it's more been about the experience and making sure the kids have that experience, and we'll figure out how to pay for it later. It always has been.

Here, the gloss, “...I know a lot of people probably say...," reflects Lisa's inference about how other consumers behave, rather than any empirical knowledge of such behavior. Since she undoubtedly does not know how "a lot of people" determine their vacation expenses, this gloss hides an important meaning in Lisa's interpretation of vacation decision making. When this gloss is combined with her claim to the idiosyncratic behavior of ignoring the costs for a vacation, another significant meaning emerges—-she perceives her family vacations as special experiences, and the commingling of money issues with the vacation decision taints and takes away from this specialness. Furthermore, her overgeneralizations, "We've never ever looked at any of our vacations in terms of financial...," and, "It always has been," underscore the importance Lisa attaches to this meaning of priceless (label) vacation experiences.

Coding caveats. Coding interview data in the manner discussed above can be challenging, as the analyst must be careful not to inject his or her beliefs or theoretical notions into the interpretation. Conducting qualitative research means becoming a translator, but in nearly any translation there is the possibility of misinterpretation of meaning. It is, arguably, impossible to eliminate bias in research, be it qualitative or quantitative, due to factors such as limitations on our measurement capabilities and the nature of the object of study, especially people. However, we can and should strive to minimize bias.

Probably the most important safeguard against the infusion of bias in qualitative research is the application by someone trained in interpretive science of a rigorous, tested method of analysis such as that outlined in this article. Adherence to a systematic analytic approach can then be supplemented with other strategies for mitigating bias. One approach is to use multiple methods and data sources - to "triangulate." For ex- 
ample, in the study of river rafting as extraordinary experience, the researchers used participant observation, focus groups, and surveys, as well as depth interviews. ${ }^{39}$ A less-involved means for monitoring potential bias is to submit the data record and provisional coding scheme to another person or group who possesses a basic understanding of the research question and method. ${ }^{40}$ Finally, some qualitative researchers strongly advocate that data and interpretations be subject to validation by participants in the study, a process known as member checks..$^{41}$ Ultimately, the best way to protect against interpretive bias is to be constantly aware that the informant's voice should be heard above that of the researcher and that the informant's perspective should guide interpretation.

\section{Developing Analytic Categories through Constant Comparison}

Analysis of the first few depth interviews for a study relies on the process of textual deconstruction, meaning-based abstraction, and conceptual labeling. However, with the reading of each new interview, the analytic strategy may gradually shift from open coding of data to comparison of new data elements with previously coded incidents that shared similar conceptual properties. ${ }^{42}$ Coding of subsequent data, therefore, becomes increasingly theoretical and abstract and is based on themes and patterns that emerge across interviews. Qualitative researchers describe this iterative process of back-andforth analysis in which new data are compared to concepts in use and new concepts are compared to previously coded data as "constant comparative analysis." This analytic process is one of the hallmarks of the interpretive method and serves to further open up the interview text and suggest important conceptual relationships.

Constant comparison facilitates the grouping of concepts into more abstract categories, which are the building blocks of a fundamental under-

\footnotetext{
${ }^{39}$ Arnould and Price, op. cit.

${ }^{40}$ Erlandson, et al., op. cit.

${ }^{41}$ Y.S. Lincoln and E.G. Guba, Naturalistic Inquiry (Beverly Hills, CA: Sage Publications, 1985).

${ }^{42}$ Strauss and Corbin, op. cit.
}

standing of a topic. Coding of interview data often nets several dozen or more conceptual labels. The next step in the analytic process is to reexamine the interviews and combine labels that were used to describe the same types of data, while being careful not to lose the subtle but important distinctions those concepts were chosen to represent. The resulting provisional coding scheme then forms the base for categorical analysis. Category development involves grouping concepts based on similarities and differences in

\section{An important safeguard against the infusion of bias in qualitative research is the application by someone trained in a rigorous, tested method of analysis.}

the properties suggested by each concept. For example, Ron and Lisa's descriptions of vacation decision making described above might be coded as "perceived uniqueness" and "priceless," respectively. These labels share the abstract property of being "extraordinary," maybe even "sacred." 43 Thus, we might categorize these textual data elements together, using the label "sacredness" to represent this category of experience. In summary, the individual concepts represent properties of an abstract category, and it is the categories that form the basis of the final stage in the research process-thematic interpretation.

\section{Interpretation of Themes}

Spiggle suggests that interpretation occurs as "a gestalt shift and represents a synthetic, holistic, and illuminating grasp of meaning, as in deciphering code." ${ }^{\prime 4}$ Open coding involves breaking down qualitative data to mine for underlying meanings, while interpretation involves building up and integrating the data into emergent categories and mapping relationships among those explanatory abstractions to develop a coherent

\footnotetext{
${ }^{43}$ R.W. Belk, M. Wallendorf, and J.F. Sherry, Jr., "The Sacred and the Profane in Consumer Behavior: Theodicy on the Odyssey," Journal of Consumer Research, Vol. 16, June 1989, pp. 1-38.

${ }^{44}$ Spiggle, p. 497.
} 
model, theory, or essential understanding. In other words, interpretation involves looking for patterns and themes that help to explain and unify the experiences of informants. Strauss and Corbin describe the first step in this interpretative process as the selection of a central categorya concept that occurs often in the data and that possesses the analytic power "...to pull the other categories together to form an explanatory whole." ${ }^{45}$

\section{Guest-satisfaction surveys have limited value, while depth interviews and inter- pretive analysis offer a means for dis- covery and enriched understanding.}

For example, in the study of positive emotion and consumer choice for vacation products, this central category was identified as otherness, a concept that is well-documented in the travel-andtourism literature. 46 "Otherness" broadly symbolizes the leisure-travel consumer's seeking of experiences that represent something other than their current situation, such as seeking better weather, new people, a relaxed environment, unique experiences, or no money worries. By interpreting consumer choice for travel products in terms of otherness, it became more clear when and how consumers experience positive emotion when they make vacation-related decisions.

\section{Conclusion}

Many hospitality-management questions are appropriately addressed with quantitative-research methods. Examples include tracking guest satisfaction via comment cards and analysis of score frequencies and means, or pricing experiments to determine demand elasticities - the heart of yield management and similar demand-based pricing models. In general, quantitative methods can be used when the research problem

\footnotetext{
${ }^{45}$ Strauss and Corbin, p. 146.

${ }^{46}$ Nelson Graburn and Roland S. Moore, "Anthropological Research on Tourism," in Travel, Tourism, and Hospitality Research, ed. J.R. Brent Richie and C.R. Goeldner (New York: John Wiley and Sons, 1994), pp. 233-242.
}

is reasonably well defined, a guiding theory is available, key constructs are known, and construct-valid measures exist. With those tools the researcher can examine and explain relationships among phenomena and test for predictive validity.

Quantitative analysis provides limited information for strategic decision making regarding many other hospitality-management issues. For instance, even the popular guest-satisfaction instrument can offer dubious managerial value. As an example, between-period variation in satisfaction mean scores is often so minimal (e.g., from a satisfaction rating of 92.4 to 93.0 ), that little direction is offered for continuous-improvement programs. Instead, managers are apt to turn to qualitative data—say, the criticisms and suggestions guests provide on comment cards-for meaningful information. Moreover, other research questions are simply not well suited to quantitative analysis for a variety of reasons, including the extraordinary or novel nature of the problem (e.g., understanding travelers' fears post 9/11), the psychological sensitivity of the research participants to the topic, or the fuzziness of the question under investigation. In situations of this kind, qualitative-research techniques such as depth interviews and interpretive analysis can offer a means for discovery and enriched understanding.

As is true of any research method, depth interviews and interpretive analysis are imperfect tools. In particular, chances for bias exist because these techniques rely on interpretation. Depth interviews also represent informants' explanations of their own experiences-a perspective on past action that is subject to memory and other distortions. Moreover, because the researcher serves as the main instrument for data collection and analysis, inappropriate use of the interviewing technique and analytic method described here by an unskilled investigator can lead to spurious findings. Conclusions derived from qualitative research are also contextually bound, which means that generalizing to a large population may be inappropriate and potentially risky. Finally, this methodology requires a considerable investment in time and energy, both for learning the methodology and using it. Understanding these limitations is important for man- 
agers who are considering a qualitative approach to solving hospitality-management issues.

On the other hand, depth interviews and interpretive analysis provide a distinct and valuable form of knowledge about hospitality customers. By employing these techniques, researchers can see beyond survey numbers and strive to understand at a deeper level what some customers think, feel, and do-and, more important, why this is so. In addition, we can develop theories about our customers' behavior that are based on their own experiences and that use their language. Such theories may form the basis for further qualitative or quantitative research or for potential strategic-management action.

In the end, the hospitality researcher must ask whether depth interviews and interpretive analysis are the right tools to answer the research question at hand. This demands deliberate assessment of costs and benefits, for instance whether the benefit of understanding a few customers at a deep level is worth the cost in terms of generalizability of the findings. It also requires a commitment on the part of the researcher and manager to develop a degree of expertise in the methods described in this article. This is not only important for individuals wishing to undertake a research project that uses depth interviews and interpretive analysis, but also for the beneficiaries of the research effort. The latter users of the research project will have to determine the value of the insights offered by the research in terms of new knowledge or enhanced ability to solve a vexing management problem. In sum, depth interviews and interpretive analysis can be powerful tools for addressing certain questions, especially the types of complex, sensitive, fuzzy problems related to human behavior that continually challenge hospitality researchers and managers alike.

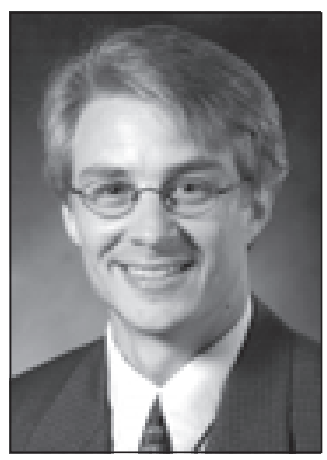

Robert J. Kwortnik, Jr., Ph.D is an assistant professor of marketing at Cornell University's School of Hotel Administration (rjk34@ cornell.edu). The author thanks William T. Ross, Jr., of the Smeal College of Business Administration at Penn State University, and Hope Jensen Schau, of the Fox School of Business and Management at Temple University, for advice on this article. 